\title{
Statcom integration in a power grid to enhance voltage stability
}

\author{
I. A Ethmane ${ }^{1}$, Ahmed Yahfdhou ${ }^{2}$, A.K. Mahmoud ${ }^{2}$, M. Maaroufi ${ }^{3}$ \\ ${ }^{1,4}$ Team in Electrical Energy and Control, Mohammed V, University, Mohammedia School of Engineers, Morocco \\ ${ }^{2,3}$ LASES, FST, UCAD, Dakar, Senegal, ${ }^{2}$ Laboratory of Research Applied to Renewable Energies, Modern University of \\ Nouakchott, Mauritania
}

\begin{tabular}{l}
\hline Article Info \\
\hline Article history: \\
Received Jan 27, 2019 \\
Revised May 1, 2019 \\
Accepted Nov 24, 2019 \\
\hline Keyword: \\
Load Growth \\
Newton- Raphson \\
STATCOM \\
MATLAB, PSS/E \\
Stability \\
\hline
\end{tabular}

\begin{abstract}
To solve load growth of an existing electrical system, we at first inject the power in system by building new electrical plants as wind, solar or thermal. And secondly in year 2030, when the system is so meshed, some customers are far away at production stations. We propose the installation of FACTS devices to enhance voltage in stability margins of power system under study. The power flow analysis using Newton Raphson method was running on Matlab and PSS/E Simulator. The results of simulation without STATCOM show the most affected buses. To improve the voltage for all these buses, reduce the power mismatches and tranmit more ative power, we insert STATCOM. STATCOM is a shunt connected FACTS application which facilitate the fast voltage control, the reactive power control and reduce the harmonics in a power system.
\end{abstract}

Copyright $@ 2019$ Institute of Advanced Engineering and Science. All rights reserved.

\section{Corresponding Author:}

Ethmane Isselem Arbih Mahmoud,

Research Team in Electrical Energy and Control 'RTEEC',

Mohammed V, University, Mohammedia School of Engineers (MSI),

Avenue: Ibn Sina B.P:765, Rabat -Morocco.

Email: ethmaneisselemarbih1966@gmail.com

\section{INTRODUCTION}

The concern for good power grid management is not only to ensure that transits power are lower than the transmission capacity. It is also necessary to monitor several technical parameters, including the voltage drop[1],[2],[3]. The voltage must remain within an authorized range at any point in the network, in all foreseeable production and consumption situations. In this context, we propose an analysis for the current and evolving production system to satisfy the domestic demand of the $33 \mathrm{kV}$ network and interconnected system. This analysis let us not only to find, but also to maintain a voltage profile in stability margins (between 0,95 and $1,05 \mathrm{pu}$ ). Another objective is, to propose a methodology for the management and control of transits power, in order to make the most efficient use of the system in a more suitable way [4],[5],[6]. To enhance voltage, we must inject reactive power $(\mathrm{Q})$ at buses where the voltage is out constraint limit. Many reactive power compensation systems exist, e.g. conventional (shunt capacitor, series capacitor, reactor etc) or Flexible Alternatif Current Systems (FACTS). Our choice is focused to FACTS systems per comparison with conventional systems. Several types of FACTS currently exist and the choice of the appropriate device depends largely on the goal to be achieved [7],[8]. Thus, to achieve these objectives, we take the following four steps:

- First step, a schematic diagram of the $33 \mathrm{KV}$ loop network with inteterconnected system is given.

- Second step, the production and load forecasts are given at 2020 to 2030 years.

- Third step, a numerical model of Newton Raphson (NR) method is resolved and programmed on MATLAB environment and PSS/E simulator for two situations (without FACTS and with FACTS devices) [9]. The results of simulations will be accompanied by discussions.

- The last step, a proposal is given on the behavior to be held for the optimal reactive power and the voltages control on an electrical distribution network. A conclusion will be given of the work. 
For the insertion of FACTS systems, it sought a stable electrical energy network which is capable even during a disturbance to provide the demand power. FACTS devices are defined by IEEE as "power electronic based controllers and other static equipment which can regulate the power flow and transmission voltage through rapid control action". In earlier days power system control was only based on generator control or capacity bank (Table 1) and there controlling ability on the transmission lines was little (neglected). Different FACTS (Table 2) controllers can influence these parameters to regulate the power flow in interconnected systems. STATCOM a shunt connected FACTS application can facilitate the fast voltage control, the reactive power control and reduce the harmonics in a power system. This is done while keeping constant and close the frequency to nominal value, the alternators speed rotation and the voltage magnitude in the various network buses [10], [11], [12], [13], [14], [15].

Table 1. Illustration of the optimum choice of STATCOM at the cost of point view.

\begin{tabular}{|c|c|c|c|c|c|}
\hline \multirow[t]{2}{*}{ Type of Equipment } & \multirow[t]{2}{*}{ Response Speed } & \multicolumn{2}{|c|}{ Voltage Support } & \multicolumn{2}{|l|}{ Cost } \\
\hline & & Capacity & availibility & & \\
\hline Generator & Fast & excellent & low & Difficult to separate & High \\
\hline Battery capacitor & & Low depends on $\mathrm{U}^{2}$ & High & $8-10 \$$ & Very low \\
\hline Compensator static & Fast & Low depends on $\mathrm{U}^{2}$ & High & $45-50 \$$ & Moderate \\
\hline STATCOM & Fast & Low depends on $\mathrm{U}^{2}$ & High & $50-55 \$$ & Moderate \\
\hline Distributed Génération & Fast & Low depends on $\mathrm{U}^{2}$ & low & Difficult to separate & High \\
\hline
\end{tabular}

Table 2. Comparison of FACTS systems in terms of technical efficiency

\begin{tabular}{|c|c|c|c|c|c|c|}
\hline \multirow[t]{3}{*}{ Problem } & \multicolumn{6}{|c|}{ FACTS Systems } \\
\hline & \multicolumn{2}{|c|}{ Shunt } & \multicolumn{2}{|c|}{ Series } & \multicolumn{2}{|c|}{ Hybrid } \\
\hline & SVC & STATCOM & SSSC & TCSC & IPFC & UPFC \\
\hline The control of the voltage (static state) & ++ & ++ & ++ & + & + & + \\
\hline The control of the voltage (dynamic state) & ++ & ++ & ++ & + & + & + \\
\hline Static stability & ++ & ++ & - & - & - & + \\
\hline Dynamic Stability & ++ & ++ & - & - & - & + \\
\hline Damping of power oscillation & ++ & ++ & ++ & ++ & + & ++ \\
\hline Transitional stability & + & ++ & - & ++ & + & ++ \\
\hline Power flow (static condition) & + & + & ++ & ++ & ++ & ++ \\
\hline Limitation of the fault current & - & - & - & - & + & + \\
\hline
\end{tabular}

\section{STRUCTURE OF SYSTEM}

\subsection{Structure of 33KV Loops of Nouakchott System}

The single-line diagram (Figure 1) represents the $33 \mathrm{KV}$ part of Noukchott network and the transmission lines to Boulenoir and Nouadhibou cities. The lines (cables) data, the values of generated and loads grow are given in Tables 3 and 4. The electrical network consists of 13 transmissions lines, 8 generators (two wind power, two solar plants, three thermal plants and 1 Dual fuel) and 6 loads at bus 2,4,5,6,7 and 9 (Figure 1).The active and reactive powers generated are given in MW and MVAR respectively. The voltage of each bus (i) is given in KV. The load bus is characterized by its active power $\mathrm{P}$ and reactive power $\mathrm{Q}$. Therefore, $(\mathrm{P}, \mathrm{Q})$ are specified, while $(\mathrm{V})$ is to be calculated. In this context, it is proposed for the North bus (1), to be slack bus. Finally, it should also be noted that a bus is numbered (i) and it is connected to (k) other buses such as those shown in Figure 1.

PG9 


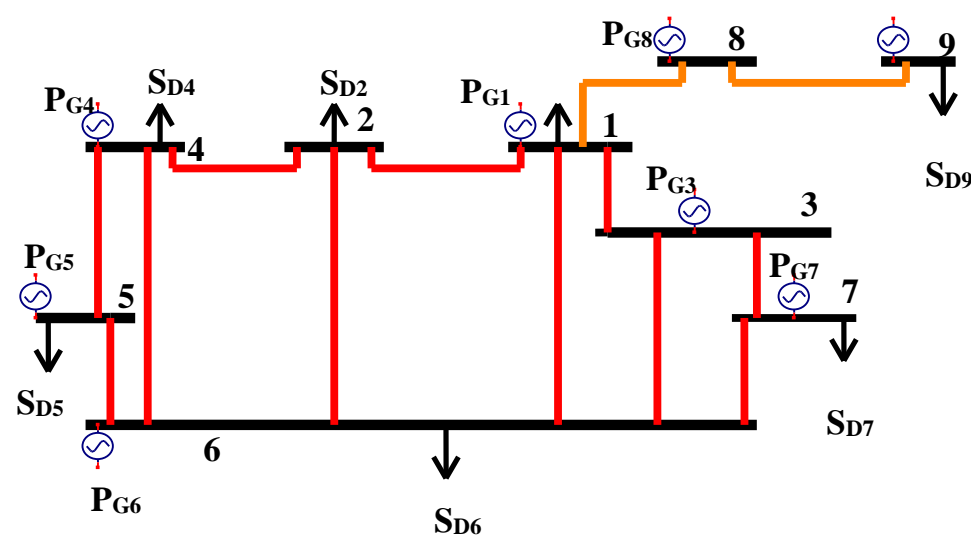

Figure 1. Simplified line diagram; of Nouakchott supply network

\subsection{Given data of system}

It is also proposed in Table 3, the active resistances $(\mathrm{R})$, the lines reactances $(\mathrm{X})$, bus voltage $(\mathrm{V})$, the lengths (L) at each bus (i) connected to bus the (k). It is also given in Table 4, the projected generation and load forecasts data of studying system at year 2020 to 2030. Active power is given in MW and reactive power in MVAR.

Table 3. Cable data of Figure 1

\begin{tabular}{ccccccc}
\hline $\mathbf{N}$ & $\mathbf{i}$ & $\mathbf{k}$ & $\mathbf{R}(\boldsymbol{\Omega})$ & $\mathbf{X}(\boldsymbol{\Omega})$ & $\mathbf{U}(\mathbf{K V})$ & $\mathbf{L}(\mathbf{k m})$ \\
\hline 1 & 1 & 2 & 0.122 & 0.167 & 33 & 6.27 \\
2 & 1 & 3 & 0.067 & 0.092 & 33 & 3.47 \\
3 & 1 & 6 & 0.024 & 0.037 & 33 & 20 \\
4 & 1 & 8 & 0.14 & 0.22 & 225 & 410 \\
5 & 2 & 4 & 0.027 & 0.037 & 33 & 13.98 \\
6 & 2 & 6 & 0.032 & 0.044 & 33 & 16.8 \\
7 & 3 & 6 & 0.061 & 0.08 & 33 & 15 \\
8 & 3 & 7 & 0.141 & 0.193 & 33 & 7.25 \\
9 & 4 & 5 & 0.17 & 0.232 & 33 & 8.72 \\
10 & 4 & 6 & 0.127 & 0.173 & 33 & 4.51 \\
11 & 5 & 6 & 0.101 & 0.15 & 33 & 5.66 \\
12 & 6 & 7 & 0.232 & 0.31 & 33 & 11.87 \\
13 & 8 & 9 & 0.14 & 0.22 & 90 & 60 \\
\hline
\end{tabular}

Table 4. Projected generation and load forecasts data [16], [17]

\begin{tabular}{|c|c|c|c|c|c|c|c|c|}
\hline \multicolumn{9}{|c|}{ Year } \\
\hline \multirow[b]{2}{*}{$\mathbf{N}$} & \multicolumn{4}{|c|}{$2020-2025$} & \multicolumn{4}{|c|}{$2025-2030$} \\
\hline & $\begin{array}{c}\mathbf{P}_{\mathbf{G}} \\
\mathbf{M W}\end{array}$ & $\begin{array}{c}\mathbf{Q}_{\mathrm{G}} \\
\text { MVAR }\end{array}$ & $\begin{array}{c}\mathbf{P}_{\mathrm{D}} \\
\mathbf{M W}\end{array}$ & $\begin{array}{c}\mathbf{Q}_{\mathrm{D}} \\
\text { MVAR }\end{array}$ & $\begin{array}{c}\mathbf{P}_{\mathbf{G}} \\
\mathbf{M W}\end{array}$ & $\begin{array}{c}\mathbf{Q}_{\mathrm{G}} \\
\text { MVAR }\end{array}$ & $\begin{array}{c}\mathbf{P}_{\mathrm{D}} \\
\mathbf{M W}\end{array}$ & $\begin{array}{c}\mathbf{Q}_{\mathrm{D}} \\
\text { MVAR }\end{array}$ \\
\hline 1 & 270 & 130.68 & & & 360 & 174.24 & & \\
\hline 2 & & & 142.55 & 81.37 & & & 734.14 & 419.05 \\
\hline 3 & 15 & 7.26 & & & 15 & 7.26 & & \\
\hline 4 & 36 & 17.42 & 6.9 & 5.86 & 36 & 17.42 & 35.53 & 30.179 \\
\hline 5 & 70 & 33.88 & 48,4 & 6.02 & 60 & 29.4 & 249.31 & 36.8 \\
\hline 6 & 199 & 96.67 & 69.48 & 36.97 & 217 & 105.149 & 357.86 & 190.39 \\
\hline 7 & 50 & 24.2 & 69.4 & 7.18 & 50 & 24.2 & 310.5 & 166.34 \\
\hline 8 & 100 & 48.4 & & & 100 & 48.4 & & \\
\hline 9 & 30 & 14.52 & 17 & 9.7 & 30 & 14.52 & 51 & 29.1 \\
\hline
\end{tabular}

\subsection{Numerical model of STATCOM}

The Static Synchronous Compensator STATCOM is one of FACTS derivate family. It uses the forcing electronic power commutation (GTO, IGBT or IGCT). A STATCOM is controlled reactive power source and improve the transient stability of systems [18]. It provides voltage support by generating or absorbing reactive power at the point of common coupling without the need of large external or capacitor banks. The basic voltage source converter scheme is shown in Figure 2.

\subsection{Mathematical model of power flow with STATCOM}


The Thevenin's equivalent circuit of the fundamental frequency operation of the switched mode voltage source inverter STATCOM and its transformer is shown in Figure 2 [18].

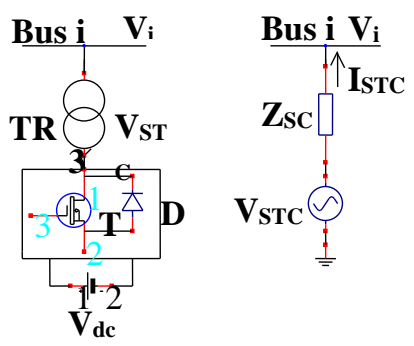

(a) (b)

Figure 2. (a) Basic schematic diagram; (b) equivalent circuit

From Figure 2, we obtain equation (1):

$$
V_{S T C}=V_{i}+Z_{S C} I_{S T C}
$$

Where $\mathrm{V}_{\mathrm{STC}}$ is STATCOM's voltage, I $\mathrm{I}_{\mathrm{STC}}$ is STATCOM's current, and $\mathrm{Z}_{\mathrm{SC}}$ is transformer impedance.

The voltage injection bound constraint of STATCOM is given by equation (2)

$$
V_{S T C(\min )} \leq V_{S T C} \leq V_{S T C(\max )}
$$

Where $\mathrm{V}_{\mathrm{STC}(\min )}$ and $\mathrm{V}_{\mathrm{STC}(\max )}$ are STATCOM's minimum and maximum voltages

Equation (1) is transformed into a power flow expression for STATCOM and power injected at bus (i) by equations (3) and (4) respectively:

$$
\begin{aligned}
& S_{S T C}=V_{S T C} I_{S T C}^{*}=V_{S T C} V_{S T C}^{*} Y_{S C}^{*}-V_{S T C} Y_{S C}^{*} V_{i} \\
& S_{i}=V_{i} I_{S T C}^{*}=V_{i} V_{i}^{*} Y_{S C}^{*}-V_{i} Y_{S C}^{*} V_{S T C}^{*}
\end{aligned}
$$

Where $\mathrm{S}_{\mathrm{STC}}$ is STATCOM's apparent power, I* ${ }^{*}$ STC is STATCOM's complex conjugate current, $\mathrm{V}^{*}{ }_{\text {STC }}$ is STATCOM's complex conjugate voltage, and $\mathrm{Y}^{*} \mathrm{sC}$ is complex conjugate of short-circuit admittance.

The voltages in rectangular coordinates system are expressed as equations (5) and (6) respectively:

$$
\begin{gathered}
V_{i}=e_{i}+j f_{i} \\
V_{S T C}=e_{S T C}+j f_{S T C}
\end{gathered}
$$

Where $e_{i}-$ is a real component ofvoltage at bus (i), $f_{i}$ is a imaginary component of voltage at bus (i), $\mathrm{e}_{\mathrm{STC}}$ is a real component of STATCOM voltage, and $\mathrm{f}_{\mathrm{STC}}$ is a imaginary component of STATCOM voltage.

The STATCOM's voltage magnitude and angle are expressed as equations (7) and (8) respectively:

$$
\begin{gathered}
\left|V_{S T C}\right|=\left(e_{S T C}^{2}+f_{S T C}^{2}\right)^{\frac{1}{2}} \\
\delta_{S T C}=\tan ^{-1}\left(\frac{f_{S T C}}{e_{S T C}}\right)
\end{gathered}
$$

The active and reactive power components for the STATCOM and bus i on the basis of equations (5) to (8) are respectively expressed by equations (9) to (12):

$$
\begin{aligned}
& P_{S T C}=G_{S C}\left\{\left(e_{S T C}^{2}+f_{S T C}^{2}\right)-\left(e_{S T C} e_{i}+f_{S T C} f_{i}\right)\right\}+B_{S C}\left(e_{S T C} f_{i}-e_{S T C} f_{i}\right) \\
& Q_{S T C}=G_{S C}\left(e_{S T C} f_{i}-f_{S T C} e_{i}\right)+B_{S C}\left\{\left(e_{S T C} e_{i}+f_{S T C} f_{i}\right)-\left(e_{S T C}^{2}+f_{S T C}^{2}\right)\right\} \\
& P_{i}=G_{S C}\left\{\left(e_{i}^{2}+f_{i}^{2}\right)-\left(e_{i} e_{S T C}+f_{i} f_{S T C}\right)\right\}+B_{S C}\left(e_{i} f_{S T C}-e_{i} f_{S T C}\right) \\
& Q_{i}=G_{S C}\left(e_{i} f_{S T C}-f_{i} e_{S T C}\right)+B_{S C}\left\{\left(e_{i} e_{S T C}+f_{i} f_{S T C}\right)-\left(e_{i}^{2}+f_{i}^{2}\right)\right\}
\end{aligned}
$$

Where $P_{\text {STC }}$ - is STATCOM's real power, QSTC - is STATCOM's reactive power, GSC - is shortcircuit conductance, $\mathrm{B}_{\mathrm{SC}}-$ is short-circuit susceptance.

The Newton-Raphson set of linearized equations for power flow equations (3), (4), (9) and (10) obtained taken into consideration the modeling of shunt-connected STATCOM at bus (i) is given by equation (13): 


$$
\left[\begin{array}{l}
\Delta P_{i} \\
\Delta Q_{i} \\
\Delta P_{S T C} \\
\Delta Q_{S T C}
\end{array}\right]=\left[\begin{array}{llll}
\frac{\partial P_{i}}{\partial e_{i}} & \frac{\partial P_{i}}{\partial f_{i}} & \frac{\partial P_{i}}{\partial e_{S T C}} & \frac{\partial P_{i}}{\partial f_{S T C}} \\
\frac{\partial Q_{i}}{\partial e_{i}} & \frac{\partial Q_{i}}{\partial f_{i}} & \frac{\partial Q_{i}}{\partial e_{S T C}} & \frac{\partial Q_{i}}{\partial f_{S T C}} \\
\frac{\partial P_{S T C}}{\partial e_{i}} & \frac{\partial P_{S T C}}{\partial f_{i}} & \frac{\partial P_{S T C}}{\partial e_{S T C}} & \frac{\partial P_{S T C}}{\partial f_{S T C}} \\
\frac{\partial Q_{S T C}}{\partial e_{i}} & \frac{\partial Q_{S T C}}{\partial f_{i}} & \frac{\partial Q_{S T C}}{\partial e_{S T C}} & \frac{\partial Q_{S T C}}{\partial f_{S T C}}
\end{array}\right]\left[\begin{array}{l}
\Delta e_{i} \\
\Delta f_{i} \\
\Delta e_{S T C} \\
\Delta f_{S T C}
\end{array}\right]
$$

\section{RESULTS AND DISCUSSION}

Table 5 shows the results of NR without and with STATCOM. It shows the optimal STATCOM location in buses and shown it impact on the system.

Table 5. Results of NR without and with STATCOM

\begin{tabular}{cccccc}
\hline \multirow{2}{*}{ Bus } & \multicolumn{2}{c}{ Without STTCOM } & \multicolumn{2}{c}{ With STATCOM } \\
\cline { 2 - 6 } & Type & Vpu & Angle $\left({ }^{\circ}\right)$ & Vpu & Angle $\left({ }^{\circ}\right)$ \\
\hline 1 & Slack & 1 & 0 & 1 & 0 \\
2 & PQ & 0.66 & -9.01 & 1.05 & -20 \\
3 & PV & 0.91 & -1.9 & 0.98 & -4.1 \\
4 & PQ & 0.59 & -12.08 & 0.99 & -21 \\
5 & PV & 0.62 & -11.02 & 1.006 & -20.5 \\
6 & PV & 0.64 & -10.15 & 1.02 & -20 \\
7 & PQ & 0.75 & -5.97 & 0.95 & -12 \\
8 & PQ & 0.98 & -0.39 & 0.98 & -0.4 \\
9 & PQ & 0.97 & -0.79 & 0.97 & -0.8 \\
\hline
\end{tabular}

The voltage profile before and after STATCOM connected are shown in Figure 3(a). It demonstrates the voltage magnitude increased for the bus 2 at 0.66 (value out limit $[0,95 ; 1,05 \mathrm{pu}]$ ) to $1.05 \mathrm{pu}$, bus 3 at 0.91 to $0.98 \mathrm{pu}$, the bus 4 at 0.59 to $0.99 \mathrm{pu}$, the bus 5 at 0.62 to $1.006 \mathrm{pu}$, the bus 6 at 0.64 to $1.02 \mathrm{pu}$, the bus 7 at 0.75 to $0.95 \mathrm{pu}$, the bus 8 and 9 are fixed to the values 0.98 and $0.97 \mathrm{pu}$ respectively.

The voltage angle before and after STATCOM connected are shown in Figure 3(b), it demonstrates the voltage angles increased for the bus 2 at -9.01 to -20 degree, bus 3 at- 1.9 to -4.1 degree, the bus 4 at -12.08 to -21 degree, the bus 5 at -11.02 to -20.5 degree, the bus 6 at -10.15 to -20 degree, the bus 7 at -5.97 to -12 degree, the bus 8 at -0.39 to -0.4 and bus 9 at -079 to -0.8 pu.

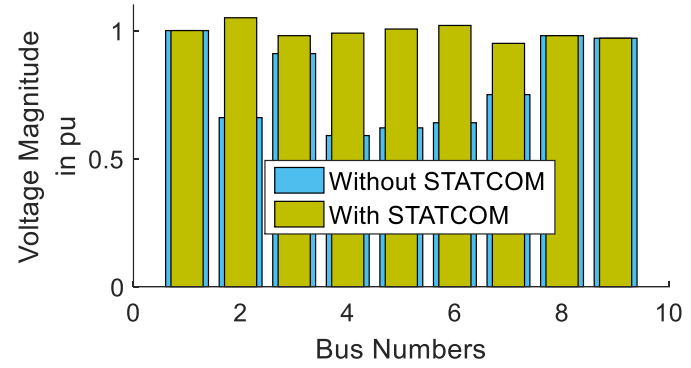

(a)

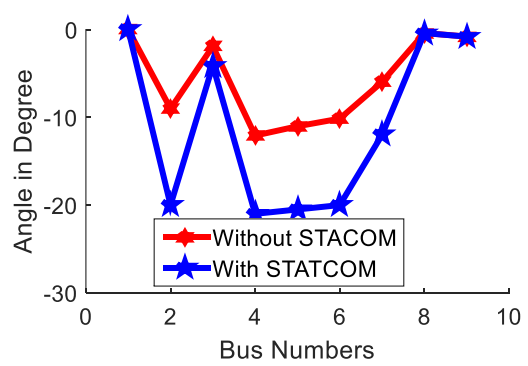

(b)

Figure 3. (a) Voltage magnitude as a function of bus numbers; (b) Voltage angle function of bus numbers

Table 6 reveals the results of power flow balances. We can notice that the total generated minuce the total load power (demand) gives the total losses of active and reactive power respectively ( $\left.\sum P_{G}=\sum P_{D}+\sum P_{\text {Losses }} ; \sum Q_{G}=\sum Q_{D}+\sum Q_{\text {Losses }}\right)$. We can also observe the value of reactive power $\left(\mathrm{Q}_{\mathrm{Sh}}\right)$ needed to minimize power losses and improve the voltage.

Table 6. Power flow balances of system [19], [20]

\begin{tabular}{cccccccc}
\hline \multirow{3}{*}{ Cases } & \multicolumn{2}{c}{ Generation } & \multicolumn{2}{c}{ To load } & \multicolumn{2}{c}{ Total Losses } & Bus shunt \\
\cline { 2 - 8 } & $\mathbf{P}_{\mathrm{G}}$ & $\mathbf{Q}_{\mathrm{G}}$ & $\mathbf{P}_{\mathbf{D}}$ & $\mathbf{Q}_{\mathrm{D}}$ & $\mathbf{P}_{\mathbf{L}}$ & $\mathbf{Q}_{\mathrm{L}}$ & $\mathbf{Q}_{\mathrm{Sh}}$ \\
& $(\mathbf{M W})$ & $(\mathbf{M V A R})$ & $(\mathbf{M W})$ & $($ MVAR) & $(\mathbf{M W})$ & (MVAR) & $($ MVAR) \\
\hline
\end{tabular}




\begin{tabular}{lccccccc}
\hline Without & 2311.2 & 1655.4 & 1711.7 & 842.6 & 599.5 & 797.1 & -2950.7 \\
$\quad$ STATCOM & & & & & & & -1 \\
With STATCOM & 2314.2 & -1311.8 & 1738.3 & 871.6 & 575.9 & 767.2 & \\
\hline
\end{tabular}

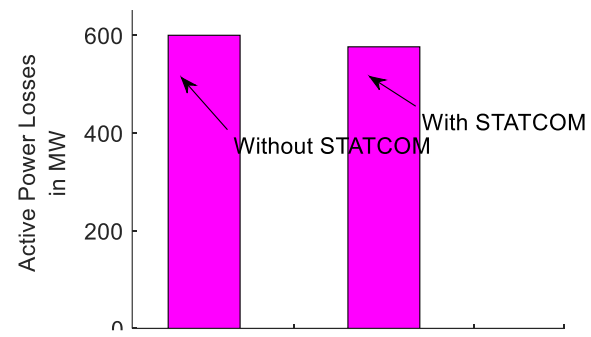

(a)

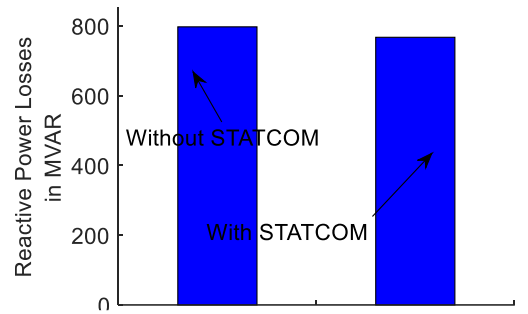

(b)

Figure 4: (a) is active power losses; (b) is reactive power losses

From Figure 4(a) there was a reduction in total active power losses from 599.5 MW to 575.9 MW, thereby improving the active power transmission lines. These results show that the STATCOM has the capability reduce active power losses on the power system. From Figure 4 (b) there was a reduction in total reactive power loss from 797.1 MVAR to 767.2 MVAR, thereby improving the active power transmission lines. These results show that the STATCOM has the capability to reduce reactive power losses on the power system.

Table 7 shows the results of delta active power, delta reactive power, errors of voltage and the delta angle with and without STATCOM as well as corresponding iteration numbers. This table also demonstrates that the NR method is more efficient per comparison with others numerical methods as GS. The number of iteration is less (4 iterations per comparison with GS 10 iterations); the convergence time remains virtually fixed and precise even if solution is complexed by the Jacobian matrix.

Table 7. Reached tolerance in 4 iterations

\begin{tabular}{ccccc|cccc}
\hline \multicolumn{5}{c|}{ With STATCOM } & \multicolumn{4}{c}{ Without STATCOM } \\
\hline It. & $\mathbf{\Delta P}(\mathbf{M W})$ & $\boldsymbol{\Delta Q}(\mathbf{M V A R})$ & $\mathbf{\Delta V ( V )}$ & $\boldsymbol{\Delta \boldsymbol { \delta } ( { } ^ { \circ } )}$ & $\mathbf{\Delta P}(\mathbf{M W})$ & $\boldsymbol{\Delta Q}(\mathbf{M V A R})$ & $\boldsymbol{\Delta V}(\mathbf{V})$ & $\Delta \boldsymbol{\delta}\left({ }^{\circ}\right)$ \\
0 & $1 \mathrm{E}-3$ & $3 \mathrm{E}-3$ & $2 \mathrm{E}-5$ & $1 \mathrm{E}-5$ & $2.2 \mathrm{E}-3$ & $3.5 \mathrm{E}-3$ & $1.6 \mathrm{E}-4$ & $2 \mathrm{E}-5$ \\
1 & $1 \mathrm{E}-4$ & $2 \mathrm{E}-3$ & $1 \mathrm{E}-5$ & $9 \mathrm{E}-6$ & $3 \mathrm{E}-4$ & $2 \mathrm{E}-4$ & $6 \mathrm{E}-5$ & $1.5 \mathrm{E}-5$ \\
2 & $9 \mathrm{E}-5$ & $1 \mathrm{E}-3$ & $9 \mathrm{E}-6$ & $8 \mathrm{E}-7$ & $1 \mathrm{E}-5$ & $1 \mathrm{E}-4$ & $5 \mathrm{E}-5$ & $1 \mathrm{E}-5$ \\
3 & 0 & 0 & 0 & 0 & 0 & 0 & 0 & 0 \\
4 & 0 & 0 & 0 & 0 & 0 & 0 & 0 & 0 \\
\hline
\end{tabular}

Figure 7 demonstrates the comparison of the voltage errors variation (a) and the delta angle (b) with and without STATCOM connected to the system as a function of ieteration numbers. However, since the magnitudes of all the voltages and their angles are not known a priori, an iterative procedure must be used to estimate the bus voltages and their angles in order to calculate the mismatches.

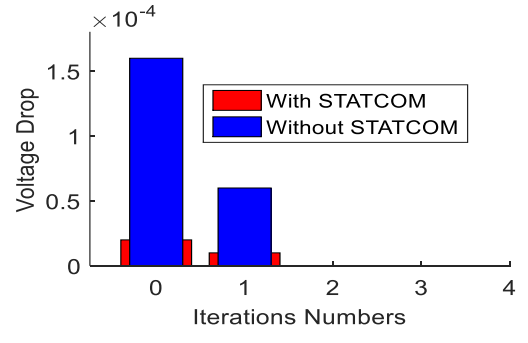

(a)

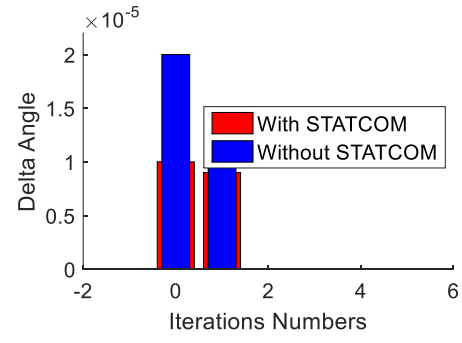

(b)

Figure 7. (a) Voltage drops function of iterations numbers; (b) Voltage angle function of iterations numbers

Moreover, Figure 8 demonstrates the relatioship of delta Pi and delta Qi with the iteration numbers. When this value stopped the variations, it said to have converged (Table 7). 


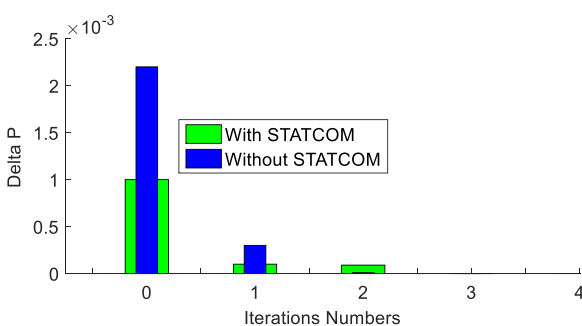

(a)

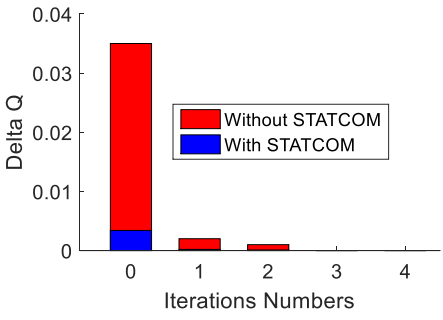

(b)

Figure 8. (a) Active power variation as a function of iterations numbers; (b) Reactive power variation as a function of iterations numbers

\section{CONCLUSION}

The simulation of load flow program on the MATLAB and PSS/E Simulator using the NR method has been done. The main information obtained is the out limit of stability all buses voltage of system except the slack bus. After insertion of STATCOM the voltage for all buses has been improved to the stability limit.The power losses compared to the NR method without STATCOM are greater than with the STATCOM (Table 6).In the end the expected disturbances and the power quality enhancement of the network in the horizon 2030 were attenuated by integration of STATCOM that is able to supply or absorb reactive power and to maintain the voltage to $1 \mathrm{pu}$. The second novelty is to replace the conventional reactive power compensation by STATCOM. Optimal location of STATCOM can be found out using Genetic Algorithm and fuzzy logic. Economic Assessment of FACTS devices against other methods can be studied.

\section{ACKNOWLEDGMENTS}

The authors like to thank the Mauritanian National Electrical Society (SOMELEC) for the given data of system. And would to thanks the reviewers who provided the valuable remarks improving the quality of paper.

\section{REFERENCES}

[1] K.K. Arshdeep, and S.B. Yadwinder, "Identification of best load flow calculation method for IEEE-30 bus system using MATLAB," International Journal of Electrical and Electronics Research, vol.3, pp. 155-161, 2015.

[2] G.W.Stagg, Computer methods in power systems analysis, Mc Grew Hill international book company: New-York, 1968.

[3] J.G. John, Power system analysis, Mc Grew Hill, New-York, 1994.

[4] S.Wei, and L. Yi, "The research of optimization in electric energy transportation based on improved imperialist competitive algorithm," Wseas Transaction. on System and Control, vol. 11, pp. 342-352, 2016

[5] C.A. Coello, " Evolutionary multi- objective optimization: on a historical of the field," Comp. Intel. Mag. IEEE, vol. 1, pp. 28-36, 2006.

[6] A. Bilel, A. Boukadoum, S. Leulmi, and T. Boukra, "Improving the Transient Stability of the Mixed AC/DC Networks with ," Indonesian Journal of Electrical Engineering and Informatics (IJEEI), Vol. 6, no. 4, pp. 477-485, 2018.

[7] G. Alexis, G. Robin, B. Alexis, and K. George, "Robust Day-Ahead Forecasting of Household Electricity Demand and Operational Challenges," Energies, vol. 11, pp. 1-18, 2018.

[8] I.A. Ethmane, M. Maaroufi, M. Abdel Kader, and A. Yahfdhou, "Optimization for Electric Power Load Forecast," IJECE, vol. 8, pp. 3453-3462, 2018.

[9] Y.Sode, et al. " Static voltage stability margin enhancement using STATCOM, TCSC and SSSC," 2005 Proceedings of IEEE/PES transmission and distribution conference and exhibition, Asia and Pacific IEEE Xplore Press Dalian, pp. 1-6,2005.

[10] O. L.Muyideen, " Incorporating STATCOM in to a Newton based optimal power flow algorithm,". Energy Power Sources, vol. 2, pp. 209-2014, 2015.

[11] S. Amaranth, G. Archita, B. Raja, and S. Sourish, "An article on flexible A.C transmission system,". IRJET, vol. 3, pp.1-6,2002.

[12] R. Natesan, et al. "Effect of STATCOM, SSSC and UPFC on voltage stability," $200436^{\text {th }}$ Southeastern symposium on system theory, IEEE-Xplore press, pp. 546-550, 2004.

[13] D.J. Gathan, GT. Heydt, "Power flow control and power flow studies for systems with FACTS devices," IEEE Transaction on Power System, vol. 13, pp. 60-65, 1998.

[14] K.K. Arshdeep, and B. YS, "FACTS based power system optimization by using Newton Raphson technique," International Journal of Emergency Research in Management \&Technology, vol. 5, pp. 1-7, 2016. 
[15] T.T. Nguyen, et al., "Application of Optimization Method for Control Coordination of PSSs and FACTS Devices to Enhance Small-Disturbance Stability,". 2006 Proc. IEEE PES 2005/2006 T\&D Conference and Exposition, pp. 1478$1485,2006$.

[16] I.A. Ethmane, et al. "Performance of STATCOM in power grid". $6^{\text {th }}$ IRSEC, IEEE Xplore presse,pp. 1-6, 2018.

[17] P.Jean, Plan directeur de production et transport de l'énergie électrique en Mauritanie entre 2011-2030," GOPAInternational Energy Consultants GmbH Leopoldsweg2, 61348 Bad Homburg, Allemagne ,2011.

[18] R.S. Joel, "Application of FACTS devices for power system transient stability enhancement. Master of sciences, Science in electrical and electronic engineering, Joma Kenyatta university of agriculture and technology, " 2016.

[19] A. A. Zakri, I. H. Rosma, and D. P H. Simanullang, " Effect of Solar Radiation on Module Photovoltaics 100 Wp With Variation of Module Slope," Indonesian Journal of Electrical Engineering and Informatics (IJEEI), vol. 6, no. 1, pp. 45-52, 2018.

[20] D.H. Mohammad, " Energy efficiency utilization of renewable energies and carbon dioxide emission: case study of G 20 countries," IET, vol. 16, pp. 143-152, 2016.

\section{BIOGRAPHY OF AUTHORS}

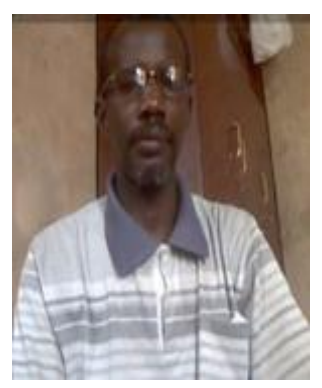

Eng. Ethmane Isselem Arbih was born in Tidjikja, Mauritania, in 1966. He received Master of Sciences degree in electrical systems and networks from Ukraina-Vinnitsa state university in 1994. He teach in secondary technical school in Nouadhibou-Mauritanian city since 13 years. He currently works in doctorate thesis. His current research interests include Electric Network, Power Systems and Energy Efficiency and automatic control. Author of five (5) manuscripts and two (2) conferences.

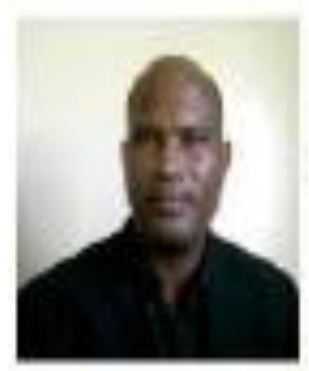

Prof. Abdel Kader Mahmoud was born in Aleg, Mauritania in 1960. He received his Master degree of Sciences in power stations in 1988 and his $\mathrm{PhD}$ degree in electrical engineering from the Technical University of Tashkent in Uzbekistan, in 1991. Then he received his second doctorate degree in renewable energy from the University of Cheikh anta Diop (UCAD), Dakar, Senegal, in 2008. Currently he is in charge of the Applied Research Laboratory of Renewable Energy (LRAER). He is the author and co-author of more than 30 scientific papers.

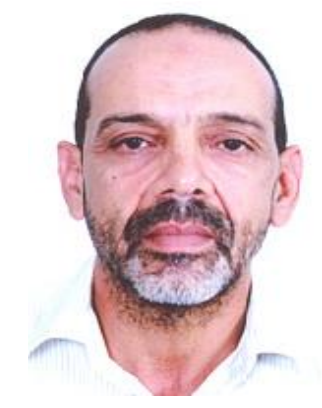

Prof. Mohamed MAAROUFI was born in Marrakech, Morocco, in 1955. He received the Engineer Diploma from the Mohammedia School of Engineers (MSI), University Mohammed V, Rabat, Morocco in 1979 and the PhD from the "Université de Liege", Liege, Belgium in 1990. He joined the Electrical Engineering Department of MSI, where is currently Professor and Researcher. His current research interests include Electric Network, Smart Grid, Renewable Energy (mainly PV and Wind), Electric Drives, Power Systems and Energy Efficiency. The Scientific Research gives 08 theses and 90 papers in International Conferences and Journals. 